\title{
An Analysis of the Effect of Academic Stress on Achievement Motivation among Senior-Secondary Students of Mathura District
}

\author{
Pragalbh Sharma ${ }^{1}$ \\ ${ }^{1}$ Assistant Professor-IBM, GLA University, Mathura (UP), India. E-mail: pragalbh.sharma @gla.ac.in
}

\begin{abstract}
Article History: Received: 11 January 2021; Accepted: 27 February 2021; Published online: 5 April 2021
\end{abstract}
\begin{abstract}
The objective of this study is to identify and examine the impact of stress on the achievement motivation of the senior secondary students. The Achievement motivation is a phenomenon of consistently attempting for success and to select target oriented success or failure activities. In the present era, a very high motivation for achievement has become very vital need for the students especially in terms of seeking admission into esteemed or reputed colleges in higher education or to become highly successful in life. The word 'Stress' is generally used to describe the feeling of not being able to manage with the things or fatigue or an unwanted pressure. The term stress in this study implies the strain, the inability or the hardship among the senior secondary students. Several studies in this field have revealed that the students are very often exposed to stress and strains which can in-turn have very severe negative impacts on their work, health, life and overall well-being. In order to complete the present study, the researcher has selected a total of 120 senior-secondary students (60 Boys \& 60 Girls) randomly from three different schools located in Mathura district. The SPSS package (v-16.0) for undertaking "One way analysis of Variance", post hoc test and t-test have been utilized to analyse the data. The findings of the present study signify that a moderate level of stress group has a better achievement motivation as compared to the high level and low levels of stress groups. While it is also observed that there exists no relevant difference between the genders (Boys \& Girls) and it is also revealed that the girl students have comparatively better achievement motivation than the boy students at senior-secondary level.
\end{abstract}

Keywords: Achievement Motivation, Stress, Motivation of Students, Unwanted Pressure, Strain, Hardship \& Fatigue.

\section{Introduction}

The present age is understood as the age of extreme stress, strain, anxiety and fatigue among all the peoples in their lives regardless of their age and gender ie., starting from the childhood till the old age. We are living in a highly dynamic environment that is ever changing at a very faster pace and that influence a rapid change in the social atmosphere that surrounds us. Youngsters today are living in an environment that is full of extreme anxiety and stress.

The youngsters are expected to perform extra-ordinarily in all the spheres of their lives. A large of these youngsters in the form of students, experiences extreme stress while they try to make a balance between the demand of study or work and their busy lives for making themselves available for their friends and family members. The students studying in senior-secondary are at the adolescent stage of their life. It is believed that the age of adolescence is the age of transition, an age in between the childhood and the adulthood. It is one of the most susceptible period for the development of a child into a youngster. Therefore, a child while entering into the age of adolescence requires a complete shift in terms of his school, family and his social life. This period is also considered very critical as the child faces various different types of problems and challenges owing to sexual development, defining the personal and professional values and getting a direction for one's life along with the development of personal, professional, educational and occupational angles of life. Also during the process of this development, students faces different types of stress that may become good or bad depending upon the capabilities of the student how he is able to cope up and manage with the stressors. A poor adjustment in terms of the different aspect of a student's life at this stage becomes stressful for most of the students and leads to stress related anxiety, acute depression and other changes relating to the alterations or modification in the behavior of these students.

Stress is one of the most common problems for both the boy and girl students at this stage of life in schools, especially at this phase of transition from school to college, and the way it is handled by them is reflected by their achievement motivation. As per a report released by the Office of Planning and Institutional Research, Villanova University in 2008, a total of 70 percent of the undergraduates experienced stress and pressure. Stress is also defined as the body's non-specific response towards the demand which is made upon it. Since it is also very evident and true, that there is no common consensus among the researchers about the definition of stress because stress may be understood by different people in many different ways depending upon one's life style, situations, stressors that one interacts with, environment and personality etc. In the bio-medical sciences, stress is mainly considered as an organism's specific response towards the adverse stimulation. In the context of Psychology, the stress is known as the process where a person and the environment interact. The effect of stress 
can be positive as well as negative. While experienced positively, the stress can become a motivator and thereby improve the quality of work life and in case if experienced negatively, it becomes a de-motivator and leads to destruction. The stress provides the medium to express the knowledge and energy to pursue happiness and on the other hand, it can also cause exhaustion or sickness, may be physical or psychological illness, attacks and accidents. Adolescent age is a very crucial age when the exposure to stress and stressors can contribute to the sustained health issues. The patterns of behavior that the students develop during this age can positively or negatively affect them in their adult age. The extreme amount of stress gives rise to many harmful ill effects in the lives of these students. The direct physiological effect of stress can affect the brain resulting into partial or complete damage to the regions specific for complex cognitive functions and can also harm the neurons. It is also believed that a moderate amount of stress and pressure on the students help them to concentrate more on the studies and other tasks assigned to them. The students at the senior secondary level encounter the stress on an everyday basis. The stress is not only present in their schools where they are expected to perform extraordinarily but also in their personal lives, family and friend relationships. Some of these stresses are good and management of stress at this level becomes overpowering. The overpowering stress pushes a student to do the things that they would not be able to accomplish normally.

The students' motivation for achievement has always remained a popular topic in the educational and research in social sciences stream also including the fields of developmental studies, behavioural studies, psychology and counseling. Motivation is a state which smoothens the activities and it is the basic drive for all the actions. It refers to the dynamics of one's behavior which involves the needs, desires and ambitions in one's life. Achievement motivation is a modern concept in the context of motivation and now most popularly used and researched in the area of education, management and social sciences. It can be described as the need for success or the realization of brilliance. Individuals will satisfy their intense needs through different ways and are driven to succeed for different reasons both internal and external. The concept of achievement motivation is developed by social psychologist McClelland to determine a strong feeling of a person for achievements in various spheres like education, culture, money, profession, personal lives etc. that satisfies the need of self esteem. It is also a deciding factor in achieving success in various different fields. Achievement goals may also affect the way a person performs a task and signify a desire to show the capabilities and skills. Thus, the achievement motivation is based on getting success and attaining all the aspirations in life. A number of psychologists have discovered that the individuals differ in regard to the extent to which they struggle for success. Moderate levels of fear of failure that causes moderate levels of stress can improve the performance and results but, a strong fear of failure that causes high stress can interfere with their performance and results. Achievement motivation forms the basis for a good life. People who are achievement motivated enjoy their life and attain their targets. Being motivated keeps the individual dynamic and helps them earn self respect. It has been reported from various researches that a greater need for achievement is also related with certain parenting behaviours. Adolescents with a greater need for achievement tend to have those parents or guardians who set greater standards for performance, reward success, persuade autonomy and freedom and maintain cordial child-parent relationships.

\section{Literature Review}

Ganesan (2001) conducted a research study and found that the stress has made a relevant contribution in the poor academic performance of the college going students.

Blumberg and Flaherty (2002) undertaken a similar study and revealed an inverse correlation between the self reported levels of stress and the academic performance of the students.

Womble (2003) also tried to find out the impact of stress over the academic performance of the college students but he did not find any relationship between the stress and academic achievement of college students.

Wombie (2005) undertaken a research study and described the impact of stress on the performance of the college going students. According to Wombie, the students going to college have to face number of obstacles in order to attain the desired academic performance and the obstacles that a student faces are called as the academic and situational constraints. These obstacles are referred to as the stressors and me one among the financial constraints, social constraints, time constraints, relationship constraints (with family members, friends and faculty members etc.)

Malik and Balda (2006) also studied and revealed a negative correlation between the levels of stress and the academic achievement of the students. It was also found that the students with more stress show poor result in terms of their academic performance.

Dowling and Torres (2009) explained that a state of emotional stress tend to have a positive impact over the academic performance of these college goers.

\section{Objectives of the Study}

- To analyze and examine the impact of stress on the achievement motivation of the senior-secondary students.

- To compare and contrast the levels of stress among the Boys and Girl Students. 
- To compare and contrast the achievement motivation of Boys and Girl Students at senior-secondary level.

\section{Research Hypothesis}

The following null hypothesis were framed and tested for the present study.

- There exists no significant impact of stress on the achievement motivation of the students at seniorsecondary level.

- There exists no significant difference in the stress levels among the Boys and Girl Students at seniorsecondary level.

- There exists no significant difference in the achievement motivations among the Boys and Girl Students at senior-secondary level.

\section{Methodology}

\section{Sample \& Sampling Technique}

In order to pursue with the objectives of the present study, a total of 120 senior secondary school students $(60$ Boys \& 60 Girls) were randomly chosen from three different schools at Mathura. The Age group of all the students was 16-17 years.

\section{Tools Used}

Perceived Stressful Life Events Scale (PSLES): The perceived stress among the students was measured using this scale. This scale was developed by Venkatesh in 1995 and was used in a similar study. It is an advanced version of the Social Readjustment Rating Scale (SRRS). PSLES consisted a total of forty five statements where each statement was responded by students on a three pointer scale with severe, moderate and nill categories. The test-retest reliability coefficients of the scale were 0.56 and the validity coefficients were found to be 0.50

Achievement Motivation (n-Ach) Scale: The achievement motivation of the students was measured by using this scale in the present study. This scale consisted of 50 items out of which 13 were negative and 37 were positive on a five pointer scale with always, frequently, sometimes, rarely and never categories. The test-retest reliability coefficients of the scale were 0.69 and the validity coefficients were found to be 0.04

\section{Statistical Techniques Used}

The research for the present study has utilized SPSS Package (v16.0) for the analysis of the data so obtained. "One way analysis of Variance" to examine the impact of stress (Independent Variable) on achievement motivation (Dependent Variable). The researcher has also applied the "post hoc test" in order to find out which level of stress (low, moderate or high) has a significant influence on achievement motivation. In the current study "t-test" was also used to examine the mean difference between the Boys and Girl students on stress level and achievement motivation.

\section{Results and Discussion}

The following table 1.1 shows that the groups of subjects contain different levels of stress, differs with respect to the achievement motivation. The table also indicates that the moderate levels of stress have better achievement motivation as compared to low and high levels of stress. Low levels of stress also have a better impact on achievement motivation as compared to the high levels of stress. The ' $F$ ' value for the stress variation is 3.794 as shown in table 1.2 which is significant at 0.5 level of confidence. Therefore, the null hypothesis stated above is rejected in favour of alternative hypothesis. This means that there is a significant impact of stress on achievement motivation of students at senior secondary level.

\section{Descriptive Statistics Table}

Table 1.1. Impact of Levels of Stress on Achievement Motivation

\begin{tabular}{lccll}
\hline Levels of Stress & $\mathrm{N}$ & Mean & Std. Deviation & Std. Error \\
\hline Low level & 42 & 121.60 & 25.640 & 3.956 \\
Moderate Level & 37 & 131.92 & 21.439 & 3.525 \\
High Level & 41 & 118.02 & 21.355 & 3.335 \\
Total & 120 & 123.56 & 23.505 & 2.146 \\
\hline
\end{tabular}

Table 1.2. F-ratio

\begin{tabular}{llllcc}
\hline & Sum of squares & df & Mean square & F & Sig. \\
\hline B/w groups & 4003.740 & 2 & 2001.870 & 3.794 & .025 \\
Within groups & 61741.851 & 117 & 527.708 & &
\end{tabular}




$\begin{array}{lrr}\text { Total } & 65745.592 & 119\end{array}$

Although the $F$ value here indicates a significant impact of stress on the overall achievement motivation of the senior-secondary students but, it was not clear that which level of stress have significant impact on the achievement motivation. Therefore, the researcher has calculated post hoc through SPSS and found that the moderate level of stress group has a better achievement motivation as compared to others. This analysis has been shown in the following table 1.3

Table 1.3. Post-hoc on Achievement Motivation

\begin{tabular}{llllll}
\hline \multirow{2}{*}{ Gabriel } & Level of stress $(\mathbf{x})$ & Level of stress $(\mathbf{y})$ & Mean difference $(\mathbf{x}-\mathbf{y})$ & Std. error & Sig. \\
& Low & Moderate & -10.324 & 5.179 & .138 \\
& & High & 3.571 & 5.043 & .858 \\
& Moderate & Low & 10.324 & 5.179 & .138 \\
& High & High & $13.895\left(^{*}\right)$ & 5.209 & .026 \\
& Low & -3.571 & 5.043 & .858 \\
& Moderate & $-13.895(*)$ & 5.209 & .026 \\
\hline
\end{tabular}

*The mean difference is significant at .05 level $(* p<.05)$

The table above suggests that the mean difference between the low and moderate level is of stress on achievement motivation is (-10.324) that is insignificant at .05 level of confidence and the mean difference between low and high level of stress on achievement motivation is (3.571) which is also insignificant. Also the mean difference between the moderate and low levels of stress is found insignificant (10.324) but the moderate and high levels of stress groups were found to have significant difference with respect to achievement motivation and the mean difference between them is (13.895). High and low levels of stress groups also have insignificant difference with mean (-3.571) but the high and moderate levels of stress groups have significant difference with respect to achievement motivation with a mean difference value (-13.895). Therefore, it is clearly indicated that low and high levels of stress have insignificant impact on achievement, motivation while on the other hand, the moderate levels of stress is very significant for greater achievement motivation among the senior-secondary students.

Table 1.4. Mean, Standard Deviation \& $t$-Values of Boys \& Girls on Stress and Achievement Motivation

\begin{tabular}{lllllllll}
\hline & Gender & N & Mean & $\begin{array}{c}\text { Std. } \\
\text { Deviation }\end{array}$ & $\begin{array}{c}\text { Std. Error } \\
\text { Mean }\end{array}$ & $\begin{array}{c}\text { t-test for equality } \\
\text { of means } \\
\text { (t-value) }\end{array}$ & $\begin{array}{c}\text { t-test for equality } \\
\text { of means } \\
\text { (Sig.) }\end{array}$ \\
\hline Stress & MALE & 60 & 92.13 & 11.577 & 1.495 & 1.879 & .063 \\
Stress & FEMALE & 60 & 86.83 & 18.532 & 2.392 & 1.879 & .063 \\
$\begin{array}{l}\text { Ach. } \\
\text { Motivation }\end{array}$ & MALE & 60 & 114.20 & 19.815 & 2.558 & -4.738 & .000 \\
$\begin{array}{l}\text { Ach. } \\
\text { Motivation }\end{array}$ & FEMALE & 60 & 132.92 & 23.315 & 3.010 & -4.738 & .000 \\
\hline
\end{tabular}

\section{$P<.001$}

The table-1.4 shows an insignificant gender difference between the levels of stress among the boys and girl students as the t-value obtained is (1.879) insignificant at .05 levels. Thus the null hypothesis already formulated is retained. This signifies that the stress is not a subject that is gender sensitive. The table also indicates that the boys and girl students also differ significantly with respect to their achievement motivation as t-value (-4.738) is significant at .01 level of confidence and thus the null hypothesis postulated above is rejected.

It is also a generalized view that the stress has always a negative impact on the achievement motivation but the present findings of the study do not provide any support to this negative relationship rather the findings of the present study indicates a positive impact of stress on the achievement motivation and also that a moderate level of stress enhances the achievement motivation among the senior secondary students. The study also shows that there is no significant gender difference in stress of the senior secondary students. Another finding of the present study shows that the girl students have better achievement motivation as compared to the boys.

\section{Conclusion}

It is an evident fact that the stress is an important part of life. People do change, struggle, act and react in different manner as a response to the stress. Therefore, the stress must be accordingly manipulated and managed as well. It is also true that stress is not always negative but positive too, it provides energy to handle the unseen situations and helps in meeting the challenges and allows us to excel in whatever field we are into. Even though some amount of stress is also beneficial and helpful, the long term after effects of the stress are resulting into the damage to our health (mentally or physically). Stress management techniques should also be used to manage and cope up with the stress. Stressors can also range from moderate stressors to severe stressors. An optimal level of 
stress can be a motivator for achievement motivation among the students. The findings of the present study have implications for the different people in the society ranging from the parents, teachers and for the students as well. The students should understand that a moderate level of stress is good for achievement motivation. So, finally to conclude, a moderate stress helps the students improve their academic performance by motivating them. Without stress, most of the students would lack motivation to study or to perform better academically. Proper counseling should be done for the senior-secondary students to utilize their talent and caliber to so that they may achieve success in their lives.

\section{References}

6. Ajayi, I.A. (1999). Analysis of teachers' job performance and secondary school students' academic achievement and their relationship. African Journal of Educational Research, 5(2), 85-90.

7. Ajwani, J.K. (1979). Problem solving behaviour in relation to personality, intelligence and age. New Delhi: ICSSR.

8. Aldwin, C., \& Greenberger, E. (1987). Cultural differences in the predictors of depression. American Journal of Community Psychology, 15, 789-813.

9. Alschuler, A. (1973). Developing achievement motivation in adolescents. New Jersey: Educational Technology Publication.

10. Blake, R.L., \& Vandiver, T.A. (1988). The association of health with stressful life changes, social supports, and coping. Family Practice Research Journal, 7(4), 205-218.

11. Blumberg, P., \& Flaherty, J.A. (1985). The influence of non-cognitive variables on student performance. Journal of Medical Education, 60, 721-723.

12. Britton, B.K., \& Tesser, A. (1991). Effects of time management practices on college grades. Journal of Educational Psychology, 83(3), 405-410.

13. Broussard, S.C., \& Garrison, M.E.B. (2004). The relationship between classroom motivation and academic achievement in elementary-school-aged children. Family \& Consumer Sciences Research, 33(2), 106-120.

14. Gupta, J. (1989). An exploratory study on some aspects of high academic stress and symptoms in 12-15 years old student. M.Sc. Thesis, Chandigarh: Punjab University.

15. Husain, A., Rashid, T., \& Jahan, M. (2001). Student stress scale. In A. Husain \& M. I. Khan (Eds.) Recent trends in human stress management. New Delhi: Global Publishing House, 254-257.

16. Jahan, M., \& Hasan, Q. (1987). A comparative study of stressfulness of life events for Indians and Americans. Advances in Psychology, 2, 1-6.

17. Johnson, D.M. (1972). Systematic introduction to the psychology of thinking. New York: Harper and Row.

18. Khan, R.L., Wilfe, D.M., Quinn, R.P., \& Snock, D. (1964). Studies in role conflict \& ambiguity. New York: Wiley.

19. Khoshaba, D.M., \& Maddi, S.R., (1999). Early experiences in hardiness development. Consulting Psychology Journal: Practice and Research, 51, 106-116.

20. Misra, R., McKean, M., West, B., \& Russo, T, (2000). Perception of academic stress among male and female college students, and compared faculty and students perceptions of students academic stress. College Student journal, 6.

21. Shah, B. (1986). Achievement motivation scale. Agra; Agra Psychological Research Cell.

22. Sharma, S. (1998). Dictionary of Psychology. Anmol Publications Pvt. Ltd. New Delhi.

23. Shonali, S. (2010). Academic self-efficacy of college students in Shimla: A preliminary study. Journal of Research: The Bede Athenaeum, 1(1), 58-66.

24. Singh, A., \& Upadhyay, A. (2008). Age and sex differences in academic stress among college students. Social Science International, 24(1), 78-88. 